\title{
The management of acute uncomplicated cystitis in adult women by family physicians in Canada
}

\author{
Warren J Mclsaac MD MSc ${ }^{1,2}$, Preeti Prakash BDS MSc ${ }^{1}$, Susan Ross PhD ${ }^{3}$
}

\begin{abstract}
WJ McIsaac, P Prakash, S Ross. The management of acute uncomplicated cystitis in adult women by family physicians in Canada. Can J Infect Dis Med Microbiol 2008;19(4):287-293.
\end{abstract}

INTRODUCTION: There are few Canadian studies that have assessed prescribing patterns and antibiotic preferences of physicians for acute uncomplicated cystitis. A cross-Canada study of adult women with symptoms of acute cystitis seen by primary care physicians was conducted to determine current management practices and first-line antibiotic choices.

METHODS: A random sample of 2000 members of The College of Family Physicians of Canada were contacted in April 2002, and were asked to assess two women presenting with new urinary tract symptoms. Physicians completed a standardized checklist of symptoms and signs, indicated their diagnosis and antibiotics prescribed. A urine sample for culture was obtained.

RESULTS: Of the 418 responding physicians, 246 (58.6\%) completed the study and assessed 446 women between April 2002 and March 2003. Most women (412 of 420, for whom clinical information about antibiotic prescriptions was available) reported either frequency, urgency or painful urination. Physicians would have usually ordered a urine culture for $77.0 \%$ of the women (95\% CI 72.7 to 80.8 ) and prescribed an antibiotic for $86.9 \%$ of the women ( $95 \%$ CI 83.3 to 90.0 ). The urine culture was negative for $32.8 \%$ of these prescriptions. The most commonly prescribed antibiotic was trimethoprim/sulfamethoxazole $(40.8 \% ; 95 \%$ CI 35.7 to 46.1 ), followed by fluoroquinolones (27.4\%; 95\% CI 22.9 to $32.3)$ and nitrofurantoin $(26.6 \%$; $95 \%$ CI 22.1 to 31.4$)$.

CONCLUSION: Empirical antibiotic prescribing is standard practice in the community, but is associated with high levels of unnecessary antibiotic use. While trimethoprim/sulfamethoxazole is the first-line empirical antibiotic choice, fluoroquinolone antibiotics have become the second most commonly prescribed empirical antibiotic for acute cystitis. The effect of current prescribing patterns on community levels of quinolone-resistant Escherichia coli may need to be monitored.

Key Words: Acute cystitis; Antibiotic prescriptions; Primary care

\section{Prise en charge de la cystite aiguë non compliquée chez les femmes adultes suivies en médecine familiale au Canada}

INTRODUCTION : Peu d'études canadiennes ont évalué les habitudes
des médecins qui soignent la cystite aiguë non compliquée et leurs
préférences en matière d'antibiotiques. Les auteurs ont analysé une étude
pancanadienne sur les femmes adultes présentant des symptômes de cystite
aiguë vues en médecine générale afin de déterminer quelles sont les
pratiques thérapeutiques actuelles et quels antibiotiques sont choisis en
première intention. MÉTHODES : Un échantillon aléatoire de 2000 membres du Collège des médecins de famille du Canada a été contacté en avril 2002 et chacun a été invité à évaluer deux femmes se présentant pour de nouveaux symptômes urinaires. Les médecins ont coché une liste standardisée de signes et symptômes; ils ont inscrit leur diagnostic et noté les antibiotiques prescrits. Un échantillon urinaire pour culture a été obtenu.

RÉSULTATS : Parmi les 418 médecins répondants, 246 (58,6\%) ont complété l'étude et évalué 446 femmes entre avril 2002 et mars 2003. La plupart des femmes (412 sur 420) se plaignaient soit de pollakiurie, de miction impérieuse ou de dysurie. Les médecins auraient en général demandé une culture urinaire chez $77,0 \%$ des femmes (IC à $95 \%, 72,7$ à 80,8 ) et prescrit un antibiotique à 86,9\% (IC à $95 \%, 83,3$ à 90,0). La culture urinaire s'est révélée négative pour 32,8\% de ces ordonnances. L'antibiotique le plus souvent prescrit a été le triméthoprime/sulfaméthoxazole (40,8 \%, IC à $95 \%$, 35,7 à 46,1), suivi des fluoroquinolones (27,4\%, IC à $95 \%, 22,9$ à 32,3) et de la nitrofurantoïne (26,6 \%, IC à $95 \%, 22,1$ à 31,4).

CONCLUSION : La prescription empirique d'antibiotiques est une pratique standard dans la communauté, mais elle est associée à des taux élevés d'utilisation superflue de l'antibiothérapie. Si le triméthoprime/sulfaméthoxazole est l'antibiotique empirique de première intention préféré, les fluoroquinolones arrivent maintenant au deuxième rang parmi les antibiotiques empiriques les plus souvent prescrits pour la cystite aiguë. L'effet des modes actuels de prescription sur les taux d'Escherichia coli résistant aux quinolones dans les communautés pourrait devoir être surveillé.
A cute uncomplicated cystitis in adult women is a common reason for visiting a primary care physician, and accounts for $5 \%$ of outpatient antibiotic prescriptions $(1,2)$. Guidelines for clinical care have promoted empirical antibiotic treatment without the need for obtaining culture results first $(3,4)$.
However, this may be associated with high rates of unnecessary prescriptions because $40 \%$ of urine cultures are negative where antibiotics are prescribed empirically (5). In recent years, uropathogen antibiotic resistance appears to be increasing $(6,7)$, although there are conflicting data from primary

${ }^{1}$ Ray D Wolfe Department of Family Medicine, Mount Sinai Hospital; ${ }^{2}$ Department of Family and Community Medicine, University of Toronto, Faculty of Medicine, Toronto, Ontario; ${ }^{3}$ Departments of Family Medicine and Community Health Sciences, Foothills Medical Centre and Department of Obstetrics and Gynaecology, Faculty of Medicine, University of Calgary, Calgary, Alberta

Correspondence and reprints: Dr Warren J McIsaac, Granovsky Gluskin Family Medicine Centre, Ray D Wolfe Department of Family Medicine, Mount Sinai Hospital, 60 Murray Street, 4th Floor, Box 25, Toronto, Ontario M5T 3L9. Telephone 416-586-4800 ext 3190,

fax 416-586-3175, e-mail wmcisaac@mtsinai.on.ca

Received for publication January 17, 2008. Accepted May 26, 2008 
care settings $(8,9)$. Also of concern has been an increase in the use of fluoroquinolone antibiotics as first-line empirical agents (10), and a rise in the rate of fluoroquinolone-resistant Escherichia coli (11). Fluoroquinolone antibiotics play an important role in the treatment of a number of serious infections (12).

In Canada, there is little known about how this common condition is managed and the current prescribing patterns of Canadian physicians. Previous Canadian studies $(13,14)$ are over 25 years old and none were national in scope. A crossCanada study of adult women with symptoms of acute cystitis seen by primary care physicians was conducted to determine current management approaches and first-line antibiotic choices.

\section{METHODS}

The study was conducted between April 2002 and March 2003. A random sample of 2000 members of The College of Family Physicians of Canada in full-time practice were contacted by mail. Physicians who agreed to participate (418 of 2000) were asked to assess up to two women, 16 years of age or older and presenting with new urinary tract symptoms suggestive of acute uncomplicated cystitis. Children, pregnant women, nursing home residents, patients on antibiotics, those unable to read English, immunocompromised patients and those with known underlying renal tract abnormalities or requiring catheters were excluded. Repeated episodes of cystitis in the same women or follow-up visits were not included.

Previous publications have reported on the results regarding uropathogen antibiotic resistance levels (15) and the validation of a cystitis decision aid in a subgroup of women with complete clinical information (16). The current report details the antibiotic prescribing patterns of Canadian family physicians. Physicians completed a standardized checklist documenting patient age, duration and type of symptoms, physical findings, diagnosis and whether antibiotics were prescribed. A urine sample for culture was obtained for all patients. Physicians were asked to test each urine sample for the presence of leukocytes and nitrites with test strips that were provided. While the dip test results were available to physicians, it was left up to each physician to decide whether they wished to use this information in treatment decisions. To determine usual practices with regard to test ordering, physicians were asked whether they normally would have ordered a urine culture in each case. Urine cultures were paid for by the study, and the physicians received a small honorarium to complete each form.

Physicians were asked to indicate their diagnosis, whether an antibiotic was prescribed, the antibiotic name, dose in milligrams, number of times the dose is needed to be taken per day and the duration of treatment. Similar diagnostic terms were grouped into the following categories; 'uncomplicated urinary tract infection (UTI)/cystitis', where one of these two terms were used; 'probable cystitis', if some degree of uncertainty or a question mark was indicated; and 'other', which included all other labels and where no diagnosis was recorded.

Consent was obtained from the women to allow a copy of the culture report to be sent to the study centre at Mount Sinai Hospital (Toronto, Ontario). A minimum colony count of $1 \times 10^{5}$ colony-forming unit ( $\mathrm{cfu}$ )/L for a single uropathogen was considered positive in the women with urinary tract symptoms (3). Empirical antibiotic prescriptions where the subsequent urine culture was negative were considered to be unnecessary prescriptions. To compare Canadian management practices with other countries, a search was undertaken in MEDLINE using the terms 'cystitis', 'urinary tract infection', 'primary health care' and 'management'. Only studies reporting data for adult women with uncomplicated cystitis were included. The bibliographies of retrieved articles were also examined for additional studies meeting these criteria.

Data analysis was carried out using SPSS version 12.0.1 (SPSS Inc, USA). Frequencies for categorical variables, means or median for continuous variables and exact 95\% CIs were determined. Unadjusted (crude) associations among variables of interest were assessed using $\chi^{2}$ testing. The study was approved by the Research Ethics Board of the Mount Sinai Hospital, Toronto, Ontario.

\section{RESULTS}

A total of 246 of 418 (58.9\%) physicians completed the study and provided either clinical information or a urine culture result for 446 women (Table 1). The mean age of the women was 44.0 years (range 16 to 99 years). More than 50\% were from Ontario, with the rest almost equally divided among British Columbia, the western provinces (Alberta, Saskatchewan and Manitoba) and the eastern provinces (New Brunswick, Nova Scotia, Prince Edward Island and Newfoundland). Because there were fewer than 10 women from Quebec, they were included with the eastern provinces. Culture results were obtained for 383 (85.9\%) visits.

Clinical information about antibiotic prescriptions was available for $420(94.2 \%)$ women. The majority of presentations were consistent with uncomplicated cystitis. Almost all women $(98.1 \%)$ had at least one of the symptoms of frequency, urgency and burning or painful urination. Almost one-half of the women presented within two days of symptom onset. Three-quarters reported that their symptoms were moderate or severe. Close to two-thirds reported having had two or more previous urine infections. Flank pain or discomfort was reported in 117 of $413(28.5 \%)$ women, and costovertebral angle tenderness on physical examination was present in 47 of 395 (11.9\%) women. A history of fever was reported by 27 of $411(6.6 \%)$ women. Only five $(1.1 \%)$ women had a history of fever and flank discomfort or costovertebral angle tenderness on examination with a positive culture. Of these, one was given a clinical diagnosis of pyelonephritis.

There were $235(61.4 \%)$ positive urine cultures in this cohort of women with typical symptoms of cystitis. In 409 urine samples tested for both leukocytes and nitrites, the urine dip was positive for either leukocytes (greater than trace) or nitrites in $311(76.0 \%)$ samples.

\section{Diagnosis, tests and antibiotic prescriptions}

Thirty-seven diagnostic labels were used by physicians (Table 2). The most common diagnosis was UTI or probable UTI (88.1\%) (eg, acute UTI, cystitis, bacterial cystitis, uncomplicated UTI and lower UTI). Physicians reported that they would have normally ordered a urine culture for $77.0 \%$ of the women (95\% CI 72.7 to 80.8).

At the office visit, an antibiotic was prescribed to $86.9 \%$ of women (95\% CI 83.3 to 90.0). A prescription was more likely if the urine dip was positive for either leukocytes or nitrites 
TABLE 1

Characteristics of adult women presenting to family physicians in Canada with symptoms suggestive of acute cystitis $(n=446)$

\begin{tabular}{|c|c|}
\hline & n (\%) \\
\hline \multicolumn{2}{|l|}{ Age, years $(n=446)$} \\
\hline $16-49$ & $283(63.5)$ \\
\hline $50-64$ & $84(18.8)$ \\
\hline $65-99$ & $79(17.7)$ \\
\hline \multicolumn{2}{|l|}{ Region/province $(n=445)^{*}$} \\
\hline British Columbia & $74(16.6)$ \\
\hline Central west $(\mathrm{AB}, \mathrm{SK}, \mathrm{MB})$ & $69(15.5)$ \\
\hline Ontario & $255(57.3)$ \\
\hline Quebec and east (NB, NS, NF, PEI) & $47(10.6)$ \\
\hline \multicolumn{2}{|l|}{ Previous history of UTI $(n=410)$} \\
\hline None & $54(13.2)$ \\
\hline One & $96(23.4)$ \\
\hline Two or more & $260(63.4)$ \\
\hline Urgency/frequency of urination or dysuria $(n=420)$ & $412(98.1)$ \\
\hline \multicolumn{2}{|l|}{ Number of days with symptoms before visit $(n=399)$} \\
\hline $1-2$ days & $184(46.1)$ \\
\hline $3-5$ days & $125(31.3)$ \\
\hline$>5$ days & $90(22.6)$ \\
\hline \multicolumn{2}{|l|}{ Severity of symptoms $(n=406)$} \\
\hline Mild or none & $114(28.1)$ \\
\hline Moderate & $196(48.3)$ \\
\hline Severe & $96(23.6)$ \\
\hline \multicolumn{2}{|l|}{ Culture $(n=383)$} \\
\hline Positive & $235(61.4)$ \\
\hline Negative & $148(38.6)$ \\
\hline \multicolumn{2}{|l|}{ Urine dip results } \\
\hline \multicolumn{2}{|l|}{ Leukocyte esterase $(n=415)$} \\
\hline Negative or trace & $117(28.2)$ \\
\hline Small positive & $67(16.1)$ \\
\hline Moderate positive or greater & $231(55.7)$ \\
\hline \multicolumn{2}{|l|}{ Nitrites $(n=409)$} \\
\hline Negative & $301(73.6)$ \\
\hline Positive & $108(26.4)$ \\
\hline
\end{tabular}

${ }^{*}$ Differing denominators reflect missing information for some variables. AB Alberta; MB Manitoba; NB New Brunswick; NF Newfoundland; NS Nova Scotia; PEI Prince Edward Island; SK Saskatchewan; QC Quebec; UTI Urinary tract infection

(290 of $313,92.7 \%$ ) than if the dip was negative for both (68 of $97,70.1 \%$; $\mathrm{P}<0.001$ ).

Prescribing information and a culture result was obtained for $357(85 \%)$ women. Of these, $32.8 \%$ were unnecessary prescriptions because the subsequent urine culture was negative. When all visits by adult women to family physicians with symptoms suggestive of acute cystitis were considered, $28.6 \%$ (102 of 357) concluded with an unnecessary antibiotic prescription.

First-line empirical antibiotic choices

The most commonly prescribed antibiotic $(40.8 \%)$ for acute cystitis in Canada was trimethoprim/sulfamethoxazole (TMP/SMX) (95\% CI 35.7\% to 46.1\%). This was prescribed for three days in 54 of 149 (36.2\%) prescriptions, for five days in $40(26.8 \%)$ prescriptions and for seven or more days in
TABLE 2

Diagnosis, tests ordered and antibiotics prescribed by physicians to women presenting with symptoms of acute cystitis

\begin{tabular}{lc}
\hline & $\mathbf{n}(\%)$ \\
\hline Diagnosis $(\mathrm{n}=446)$ & $354(79.4)$ \\
UTI/cystitis & $39(8.7)$ \\
Probable UTI & $15(3.4)$ \\
Other & $38(8.5)$ \\
No diagnosis & \\
Tests ordered* $(\mathrm{n}=418)^{\dagger}$ & $322(77.0)$ \\
Urine culture tests & \\
Antibiotic prescriptions ( $=420)$ & $55(13.1)$ \\
None & $365(86.9)$ \\
Prescribed & \\
Antibiotic choices ( $\mathrm{n}=365)$ & $149(40.8)$ \\
TMP/SMX & $100(27.4)$ \\
Quinolones & $97(26.6)$ \\
Nitrofurantoin & $10(2.7)$ \\
Penicillins ${ }^{\ddagger}$ & $7(1.9)$ \\
Fosfomycin & $2(0.6)$ \\
TMP & $102(32.8)$ \\
Unnecessary antibiotic prescriptions $§(n=311)$ &
\end{tabular}

*Determined by asking physicians, "Would you have normally ordered a urine culture test?"; †Different denominators reflect missing data for some questions; ; Amoxicillin and ampicillin; §Prescription given, but urine culture negative. TMP/SMX Trimethoprim/sulfamethoxazole; UTI Urinary tract infection

$55(36.9 \%)$ prescriptions. There were no differences in duration of antibiotics for women younger than 65 years of age compared with those 65 years of age or older (mean of 5.1 days versus 5.4 days respectively, $\mathrm{P}=0.50$ ). There was a trend for women younger than 50 years of age - they were more likely to be prescribed TMP/SMX for three days (40 of $98,40.8 \%$ ) compared with older women ( 14 of $51,27.5 \% ; \mathrm{P}=0.11$ )

Fluoroquinolone antibiotics were the second most commonly prescribed empirical antibiotic (27.4\%; 95\% CI 22.9 to 32.3 ). The fluoroquinolones prescribed were ciprofloxacin (50 of 100, $50.0 \%)$, norfloxacin $(n=44,44.0 \%)$ and levofloxacin $(n=6$, $6.0 \%)$. Where duration of use was recorded $(n=99)$, this was equally divided between three days ( 37 of $99,37.4 \%$ ), five days $(n=29,29.3 \%)$ and seven or more days $(n=33,33.3 \%)$. There was no difference in the use of fluoroquinolone antibiotics with regard to age - 21 of $65(32.3 \%)$ women 65 years of age or older were prescribed fluoroquinolones empirically, compared with 21 of $68(30.9 \%)$ women 50 to 64 years of age, and 58 of $232(25 \%)$ women younger than 50 years of age $(\mathrm{P}=0.39)$. A fluoroquinolone prescription was more likely if there was a previous history of one UTI (20 of 77, 26.09\%) or two or more UTIs (69 of $231,29.9 \%$ ), compared with no history of previous UTIs (six of $49,12.2 \% ; \mathrm{P}=0.04$ ).

Nitrofurantoin was prescribed as often as fluoroquinolone antibiotics (26.6\%; 95\% CI 22.1 to 31.4). This was most commonly prescribed as the $100 \mathrm{mg}$ extended-release macrocrystal forms taken twice daily (93 of 97, 95.6\%). Most prescriptions for nitrofurantoin were for seven days ( 52 of 97 , $53.6 \%$ ), but for 45 women (46.4\%), the duration of nitrofurantoin prescription was for less than the recommended seven days $(3,17)$. In $19(19.6 \%)$ prescriptions, the duration 
TABLE 3

Rates of antibiotic prescription, culture ordering and antibiotic choices by region

\begin{tabular}{lcccrr}
\hline & $\begin{array}{c}\text { Canada, } \\
\mathbf{n ~ ( \% )}\end{array}$ & $\begin{array}{c}\text { British Columbia, } \\
\mathbf{n}(\%)\end{array}$ & $\begin{array}{c}\text { Central west (AB, MB, SK), } \\
\mathbf{n}(\%)\end{array}$ & $\begin{array}{c}\text { Ontario, } \\
\mathbf{n}(\%)\end{array}$ & $\begin{array}{c}\text { Quebec and east, } \\
\text { (NB, NS, NF, PEI), n (\%) }\end{array}$ \\
\hline Prescribed antibiotics & $364 / 420(86.9)$ & $59 / 70(84.3)$ & $61 / 65(93.8)$ & $203 / 239(84.9)$ & $41 / 45(91.1)$ \\
Ordered culture tests & $322 / 418(77.0)^{*}$ & $42 / 69(60.9)$ & $45 / 65(69.2)$ & $208 / 238(87.4)$ & $27 / 45(60.0)$ \\
Antibiotic choices & & & & & \\
PMP/SMX & $148 / 345(43.1)$ & $33 / 59(55.9)$ & $25 / 56(44.6)$ & $69 / 197(36.1)$ & $21 / 39(53.8)$ \\
Fluoroquinolones & $100 / 345(28.9)$ & $14 / 59(23.7)$ & $18 / 56(32.1)$ & $55 / 191(28.8)$ & $13 / 39(33.3)$ \\
Nitrofurantoin & $97 / 345(28.0)$ & $12 / 59(20.3)$ & $13 / 56(23.2)$ & $67 / 191(35.1)$ & 0.022 \\
\hline
\end{tabular}

*Different denominators reflect complete information for both region and comparison variables. AB Alberta; MB Manitoba; NB New Brunswick; NF Newfoundland; NS Nova Scotia; PEI Prince Edward Island; SK Saskatchewan; TMP/SMX Trimethoprim/sulfamethoxazole

prescribed was three days. There was no difference in the use of nitrofurantoin by patient age ( $\mathrm{P}=0.56$, data not shown).

None of these antibiotics were prescribed for one day. Fosfomycin, which can be prescribed for one day (3), was used infrequently (seven of $365,1.9 \%$ ). There was no difference in unnecessary prescriptions with regard to antibiotic type $(\mathrm{P}=0.42$, data not shown).

\section{Regional differences}

There was no difference with regard to region in the proportion of women with symptoms suggestive of acute cystitis who were prescribed an antibiotic $(\mathrm{P}=0.20$, Table 3$)$. Family physicians in Ontario were most likely to routinely order urine cultures. There were some differences in the antibiotics prescribed across the country. In Ontario, TMP/SMX was less likely to be prescribed than in other regions $(\mathrm{P}=0.02)$; nitrofurantoin was more likely to be prescribed in managing acute cystitis $(\mathrm{P}=0.009)$.

\section{International comparisons}

The proportion of women with acute cystitis who were prescribed antibiotics empirically in studies from other countries ranged from $56 \%$ to $82 \%$ in North America $(5,10,18-21)$, and from $56 \%$ to $96 \%$ in Europe $(22-25,27,28,30)$ and Israel $(26,29)$ (Tables 4 and 5). TMP/SMX was prescribed at levels similar to Canada in the United States (24\% to 38\%), as well as Germany (46\%), whereas TMP/SMX was infrequently prescribed (4\% to $7 \%)$ in the United Kingdom (UK) and Italy. TMP accounted for $61 \%$ of prescriptions in the UK and $39 \%$ in Sweden. In Italy, fosfomycin accounted for 34\% of empirical prescriptions. Fluoroquinolone antibiotics as first-line treatment ranged from $21 \%$ to $53 \%$ in all countries except the UK, where they were infrequently prescribed. Nitrofurantoin was also commonly prescribed in the United States and Israel (15\% to $30 \%$ ), but was infrequently prescribed in the UK, Sweden, Germany and Italy (2\% to $4 \%$ ).

\section{DISCUSSION}

Most adult women in Canada with symptoms suggestive of acute cystitis are prescribed antibiotics empirically by family physicians. This is consistent with current expert recommendations (3). However, one in three antibiotic prescriptions are unnecessary because the urine culture will be negative for infection. In addition, although experts advise that a urine culture is not needed if women have typical symptoms of cystitis and antibiotics are prescribed, the majority of Canadian family physicians still continue to order a urine culture. TMP/SMX is the antibiotic of choice, but fluoroquinolone antibiotics have become the second most commonly prescribed antibiotic for acute cystitis in the community.

There have been few previous Canadian studies on the management of cystitis, and most have been regional in scope $(5,13,14)$. A 1975 study (13) from London, Ontario, found that antibiotics were prescribed in $51 \%$ of visits, predominately sulfonamides and nitrofurantoin. A 1981 study from Kingston, Ontario, found that $72 \%$ of persons were prescribed an antibiotic, but fewer than one-half had a positive culture (14). These studies are difficult to compare with the current study because one study included men (13), while the other included children (14). Both studies were retrospective and used a bacteriological definition of $1 \times 10^{5} \mathrm{cfu} / \mathrm{mL}$ $\left(1 \times 10^{8} \mathrm{cfu} / \mathrm{L}\right)$, whereas the current study used a definition of $1 \times 10^{5} \mathrm{cfu} / \mathrm{L}$ or more for a single uropathogen in a symptomatic woman (3). A study from Toronto, Ontario, reported that $87 \%$ of women had a urine culture ordered, $81 \%$ were prescribed antibiotics empirically and $40 \%$ had a negative urine culture (5). This is similar to the current national study in which $77 \%$ of women had a urine culture ordered, $87 \%$ were prescribed antibiotics and $33 \%$ of prescriptions were unnecessary.

Although there are some regional differences, the firstline empirical antibiotic choice for acute cystitis in Canada is TMP/SMX, consistent with current expert guidelines (3). However, fluoroquinolone antibiotics have become the second most frequently prescribed antibiotic for acute cystitis, along with nitrofurantoin. This trend toward increased community use of fluoroquinolone antibiotic use in general, and in acute cystitis in particular has been noted both in Canada $(31,32)$ and in other countries (10). Concern has been expressed that this may promote more widespread fluoroquinolone resistance and limit the effectiveness of these antibiotics in the treatment of serious and complicated infections $(12,33,34)$. Currently, fluoroquinolone antibiotics are considered second-line therapies due to their cost and also to limit fluoroquinolone resistance $(3,17,34)$. While physicians may be prescribing fluoroquinolone antibiotics due to concerns about $E$ coli resistance to TMP/SMX, this remains below $20 \%$ in Canada $(15,17,35)$ - the level at which expert recommendations suggest other antibiotics should be considered (3).

Some problems were identified regarding the duration of some antibiotic prescriptions. While TMP/SMX is approved for three-day therapy, seven or more days are recommended when complicating factors are present (3). However, in 
TABLE 4

North American studies on the management of urinary tract infection in women

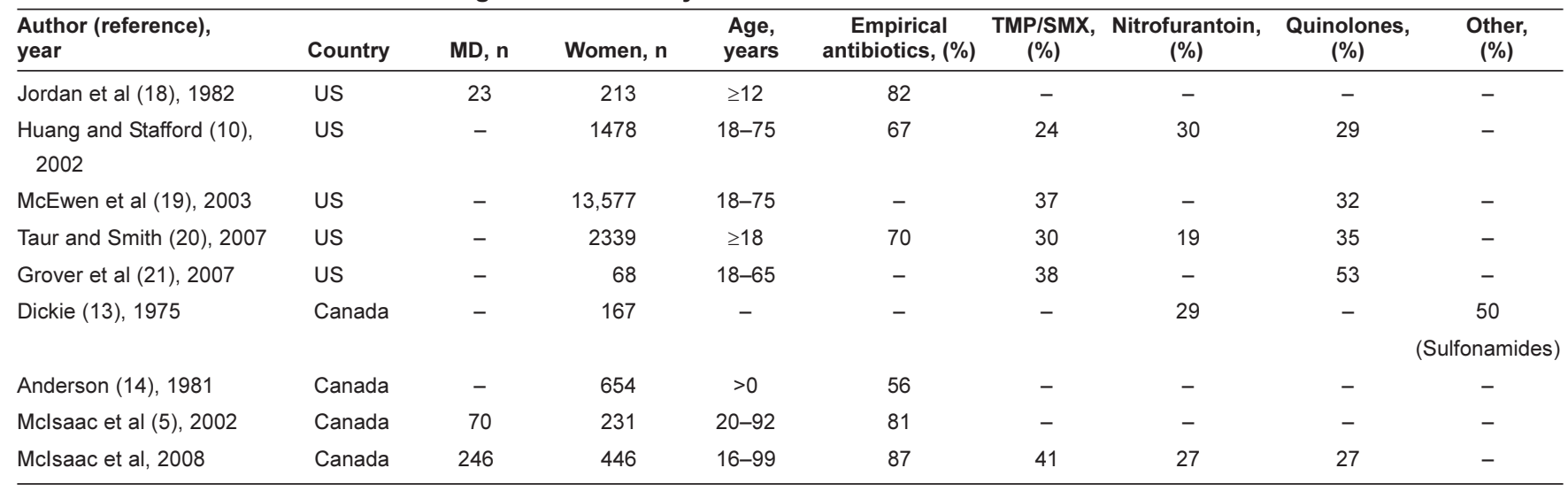

MD Medical doctor; TMP/SMX Trimethoprim/sulfamethoxazole; US United States

TABLE 5

International studies on the management of urinary tract infection in women

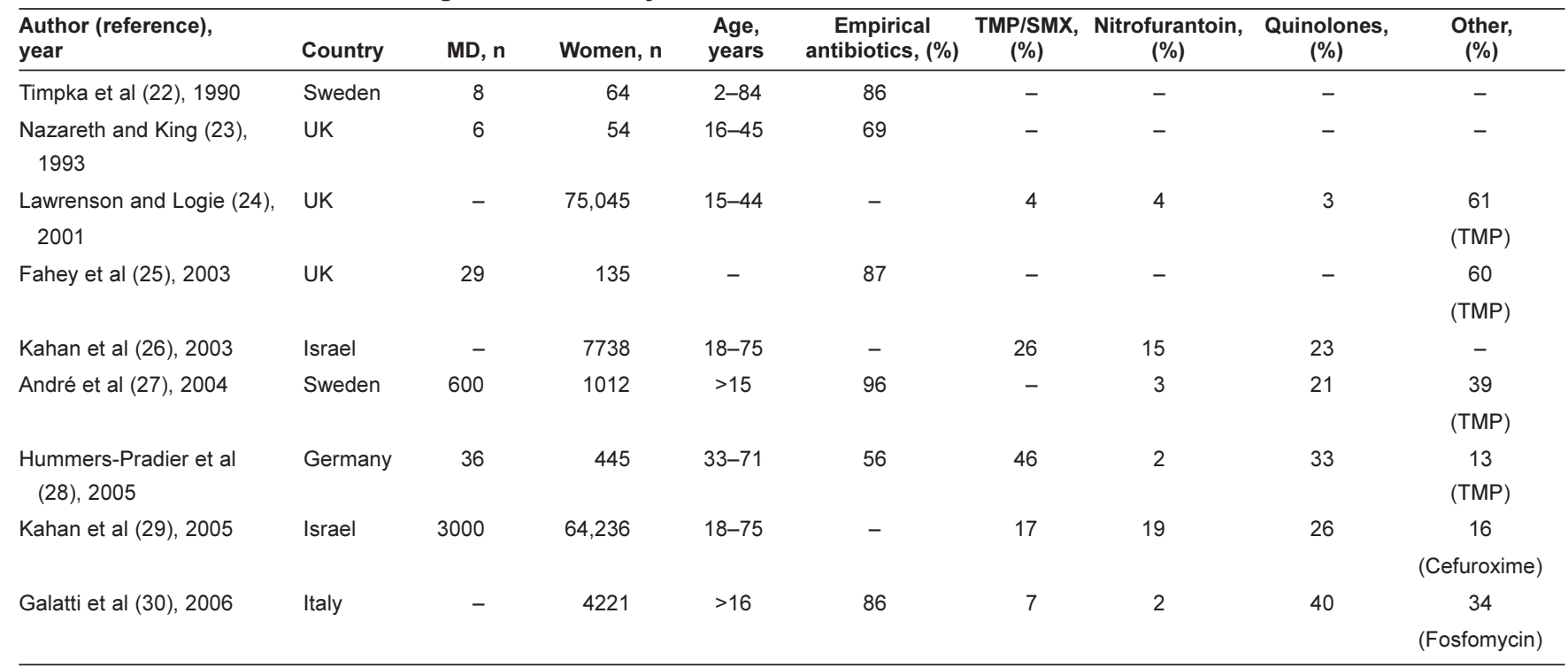

MD Medical doctor; TMP/SMX Trimethoprim/sulfamethoxazole; UK United Kingdom

almost one-quarter of instances, the duration prescribed was five days. Similarly, fluoroquinolones can be used either for short-course three-day treatment in uncomplicated cases or longer seven-day regimens, but $29 \%$ of the time it was prescribed for five days. The use of nitrofurantoin for less than seven days has generally not been supported by expert recommendations $(3,17)$; although, a recent trial $(36)$ has reported that five days of nitrofurantoin is equivalent to three days of TMP/SMX. However, family physicians prescribed this antibiotic for three days in $20 \%$ of cases. We also did not find a difference in duration of use in older women compared with younger women. Whereas a three-day treatment with TMP/SMX or fluoroquinolones is considered appropriate for uncomplicated cases of acute cystitis, the Infectious Diseases Society of America (IDSA) expert guideline (3) suggests longer courses of treatment may be warranted in older women.
Compared with other countries, Canada has high rates of empirical antibiotic use and fluoroquinolone use. Whereas TMP is a frequent first-line agent in the UK and fosfomycin in Italy, TMP/SMX remains the most frequently prescribed firstline agent for cystitis in Canada. The IDSA guideline lists TMP/SMX and TMP as similarly effective first-line choices for empirical prescribing, along with nitrofurantoin (3). The high rate of TMP use in the UK is due to a regulatory restriction placed on the use of TMP/SMX (37). The IDSA lists unresolved issues of efficacy and side effects of fosomycin compared with other first-line agents as barriers to more widespread use (3).

While these results represent the management of acute cystitis in 2002/2003, it is possible that there have been changes in management practices since that time. However, the present study is the first national study on the management of acute cystitis in the community in Canada, and also 
the most recent. An additional limitation is that fewer than $15 \%$ of physicians who were contacted contributed data. The practices of these physicians may not be representative of all family physicians. However, physicians who volunteer for studies are usually considered to demonstrate more optimal prescribing habits, which suggests that these results represent conservative estimates of current Canadian practices. In addition, physicians had access to urine dip test results at the time that they made their prescribing decisions. Still, $88 \%$ of women received antibiotics and $33 \%$ were unnecessary. The choice of fluoroquinolone antibiotics may have been related to physician awareness of factors such as recent antibiotic use or resistance to a first-line antibiotic with a previous infection. Indeed, physicians were more likely to prescribe fluoroquinolone antibiotics if there was a history of previous UTI, a factor that was associated with multidrug antibiotic resistance in a previous report from this study (15).

\section{REFERENCES}

1. Fihn SD. Clinical practice. Acute uncomplicated urinary tract infection in women. N Engl J Med 2003;349:259-66.

2. Gonzales R, Steiner JF, Sande MA. Antibiotic prescribing for adults with colds, upper respiratory tract infections, and bronchitis by ambulatory care physicians. JAMA 1997;278:901-4.

3. Warren JW, Abrutyn E, Hebel JR, Johnson JR, Schaeffer AJ, Stamm WE. Guidelines for antimicrobial treatment of uncomplicated acute bacterial cystitis and acute pyelonephritis in women. Infectious Diseases Society of America (IDSA). Clin Infect Dis 1999;29:745-58.

4. Bent S, Nallamothu BK, Simel DL, Fihn SD, Saint S. Does this woman have an acute uncomplicated urinary tract infection? JAMA 2002;287:2701-10.

5. McIsaac WJ, Low DE, Biringer A, Pimlott N, Evans M, Glazier R. The impact of empirical management of acute cystitis on unnecessary antibiotic use. Arch Intern Med 2002;162:600-5.

6. Gupta K, Scholes D, Stamm WE. Increasing prevalence of antimicrobial resistance among uropathogens causing acute uncomplicated cystitis in women. JAMA 1999;281:736-8.

7. Zhanel GG, Karlowsky JA, Harding GK, et al. A Canadian national surveillance study of urinary tract isolates from outpatients: Comparison of the activities of trimethoprim-sulfamethoxazole, ampicillin, mecillinam, nitrofurantoin, and ciprofloxacin. The Canadian Urinary Isolate Study Group. Antimicrob Agents Chemother 2000;44:1089-92.

8. Richards DA, Toop LJ, Chambers ST, et al. Antibiotic resistance in uncomplicated urinary tract infection: Problems with interpreting cumulative resistance rates from local community laboratories. NZ Med J 2002;115:12-4.

9. McNulty CA, Richards J, Livermore DM, et al. Clinical relevance of laboratory-reported antibiotic resistance in acute uncomplicated urinary tract infection in primary care. J Antimicrob Chemother 2006;58:1000-8.

10. Huang ES, Stafford RS. National patterns in the treatment of urinary tract infections in women by ambulatory care physicians. Arch Intern Med 2002;162:41-7.

11. Karlowsky JA, Kelly LJ, Thornsberry C, Jones ME, Sahm DF. Trends in antimicrobial resistance among urinary tract infection isolates of Eshericia coli from female outpatients in the United States. Antimicrob Agents Chemother2002;46:2540-5.

12. Neuhauser MM, Weinstein RA, Rydman R, Danziger LH, Karam G, Quinn JP. Antibiotic resistance among gram-negative bacilli in US intensive care units. Implications for fluoroquinolone use. JAMA 2003;289:885-8.

13. Dickie GL. Symptomatology of urinary tract infections. Can Fam Phys 1975;21:51-7.

14. Anderson JE. Initial treatment decisions in urinary tract infection. Can Fam Phys 1981;27:1909-12.

15. J McIsaac W, Mazzulli T, Moineddin R, Raboud J, Ross S. Uropathogen antibiotic resistance in adult women presenting
The present is the first national study on the management of acute cystitis in adult women in Canada by family physicians. Empirical antibiotic prescribing is standard practice in the community, but is associated with high levels of unnecessary antibiotic use. The relationship between antibiotic overuse and the promotion of antibiotic resistance (38) raises the issues of whether empirical antibiotic treatment in acute cystitis needs to be reconsidered. Alternatively, more precise diagnostic strategies that limit unnecessary antibiotic prescriptions could be a useful approach in primary care (16). Fluoroquinolone antibiotics are now widely used as first-line empirical treatment for acute cystitis across Canada. The effect of this trend on community levels of fluoroquinolone-resistant E coli needs to be monitored.

FUNDING: The present study was funded by the Canadian Institutes of Health Research, grant \#MOP-53290. to family physicians with acute uncomplicated cystitis. Can J Infect Dis Med Microbiol 2004;15:266-70.

16. McIsaac WJ, Moineddin R, Ross S. Validation of a decision aid to assist physicians in reducing unnecessary antibiotic drug use for acute cystitis. Arch Intern Med 2007;167:2201-6.

17. Nicolle L, Anderson PA, Conly J, et al. Uncomplicated urinary tract infection in women. Current practice and the effect of antibiotic resistance on empiric treatment. Can Fam Phys 2006;52:612-8.

18. Jordan S, Wilcox GM, Wasson JH. Urinary tract infection in women visiting rural primary care practices. J Fam Pract 1982;15:427-9.

19. McEwen LN, Farjo R, Foxman B. Antibiotic prescribing for cystitis: How well does it match published guidelines? Ann Epidemiol 2003; 13:479-83.

20. Taur Y, Smith MA. Adherence to the Infectious Diseases Society of America guidelines in the treatment of uncomplicated urinary tract infection. Clin Infect Dis 2007;44:769-74.

21. Grover ML, Bracamonte JD, Kanodia AK, et al. Assessing adherence to evidence-based guidelines for the diagnosis and management of uncomplicated urinary tract infection. Mayo Clin Proc 2007;82:181-5.

22. Timpka T, Bjurulf P, Buur T. Audit of decision-making regarding female genitourinary infections in outpatient practice. Scand J Infect Dis 1990;22:49-57.

23. Nazareth I, King M. Decision making by general practitioners in diagnosis and management of lower urinary tract symptoms in women. BMJ 1993;306:1103-6.

24. Lawrenson RA, Logie JW. Antibiotic failure in the treatment of urinary tract infections in young women. J Antimicrob Chemother 2001;48:895-901.

25. Fahey T, Webb E, Montgomery AA, Heyderman RS. Clinical management of urinary tract infection in women: A prospective cohort study. Fam Pract 20:1-6.

26. Kahan E, Kahan NR, Chinitz DP. Urinary tract infection in women - physician's preferences for treatment and adherence to guidelines: A national utilization study in a managed care settting. Eur J Clin Pharmacol 2003;59:663-8.

27. André M, Mölstad S, Lundborg CS, Odenholt I; Swedish Study Group on Antibiotic Use. Management of urinary tract infections in primary care: A repeated 1-week diagnosis-prescribing study in five counties in Sweden in 2000 and 2002. Scand J Infect Dis 2004;36:134-8.

28. Hummers-Pradier E, Ohse AM, Koch M, Heizmann WR, Kochen MM. Management of urinary tract infections in female general practice patients. Fam Pract 2005;22:71-7.

29. Kahan NR, Friedman NL, Lomnicky Y, et al. Physician speciality and adherence to guidelines for the treatment of unsubstantiated uncomplicated urinary tract infection among women. Pharmacoepidem Drug Safety 2005;14:357-61. 
30. Galatti L, Sessa A, Mazzaglia G, et al. Antibiotic prescribing for acute and recurrent cystitis in primary care: A 4 year descriptive study. J Antimicrob Chemother 2006;57:551-6.

31. Carrie AG, Metge CJ, Zhanel GG. Antibiotic use in a Canadian province, 1995-98. Ann Pharmacother 2000;34:459-64.

32. Patrick DM, Marra F, Hutchinson J, Monnet DL, $\mathrm{Ng} \mathrm{H}$, Bowie WR. Per capita antibiotic consumption: How does a North American jurisdiction compare with Europe? Clin Infect Dis 2004:39:11-7.

33. Bakken JS. The fluoroquinolones: How long will their utility last? Scand J Infect Dis 2004;36:85-92.

34. Hooton TM, Besser R, Foxman B, Fritsche TR, Nicolle LE. Acute uncomplicated cystitis in an era of increasing antibiotic resistance: A proposed approach to empirical therapy. Clin Infect Dis 2004;39:75-80.

35. McIsaac WJ, Mazzulli T, Permaul J, Moineddin R, Low DE. Community-acquired antibiotic resistance in urinary isolates from adult women in Canada. Can J Infect Dis Med Microbiol 2006; 17:337-40.

36. Gupta K, Hooton TM, Roberts PL, Stamm WE. Short-course nitrofurantoin for the treatment of acute uncomplicated cystitis in women. Arch Intern Med 2007;167:2207-12.

37. Co-trimoxazole use restricted. Drug Ther Bull 1995;33:92-3.

38. Magee JT, Pritchard EL, Fitzgerald KA, Dunstan FDJ,

Howard AJ. Antibiotic prescribing and antibiotic resistance in community practice: Retrospective study, 1996-8. BM] 1999;319:1239-40. 


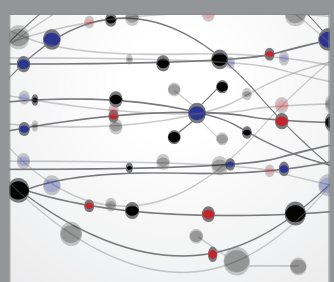

The Scientific World Journal
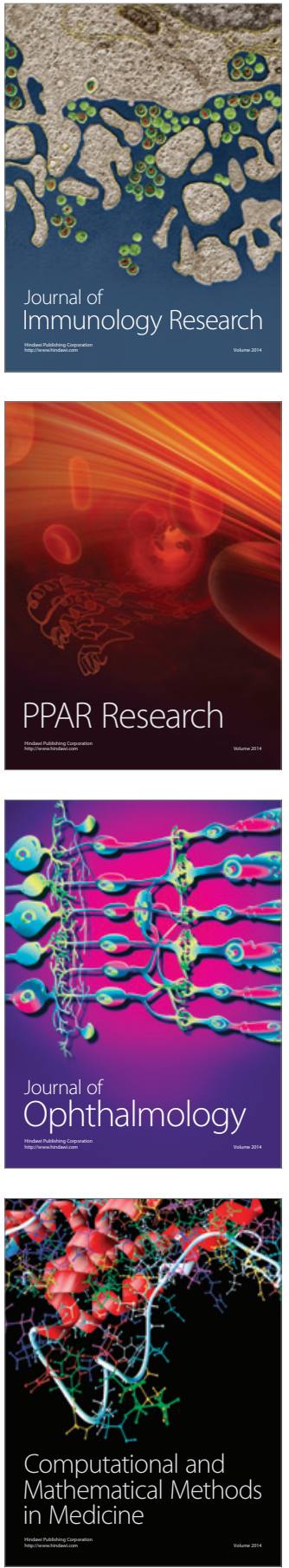

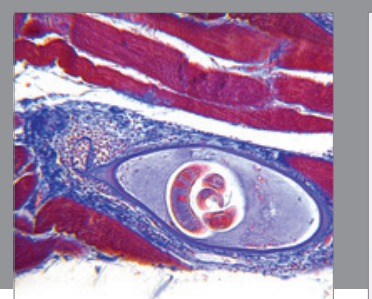

Gastroenterology Research and Practice

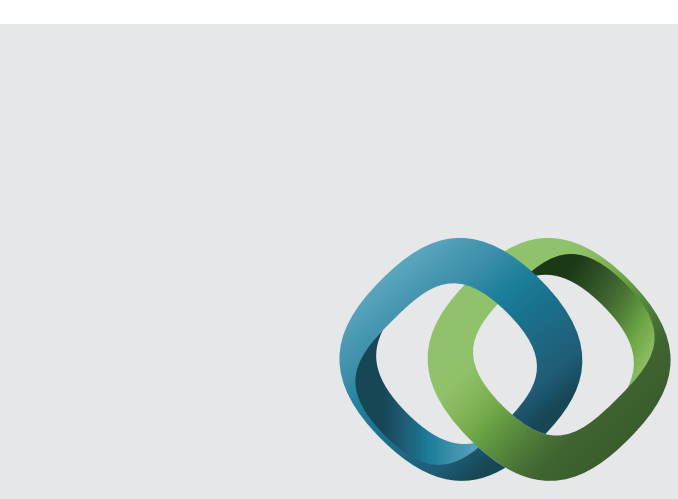

\section{Hindawi}

Submit your manuscripts at

http://www.hindawi.com
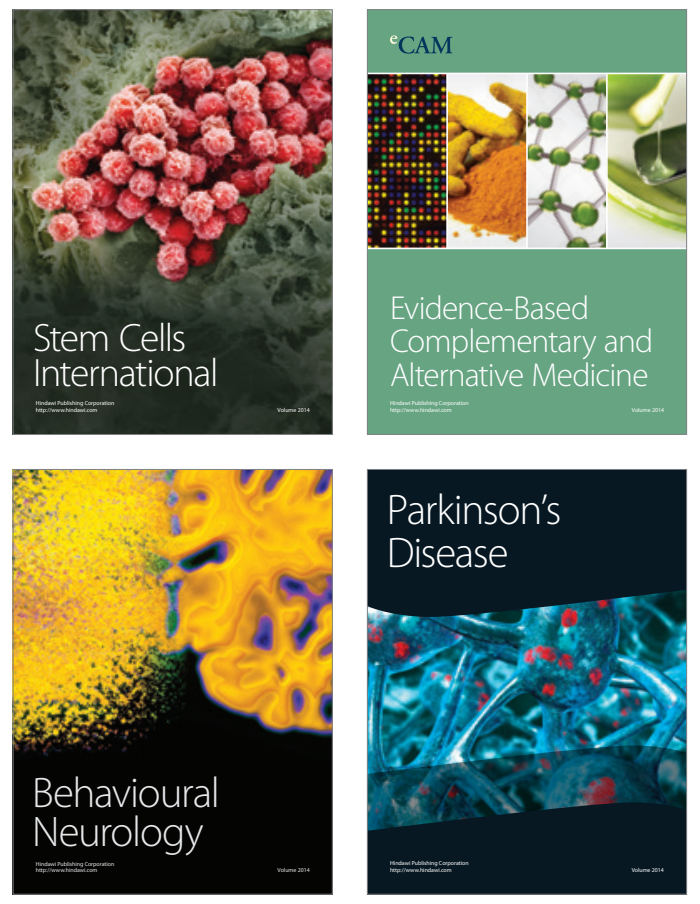
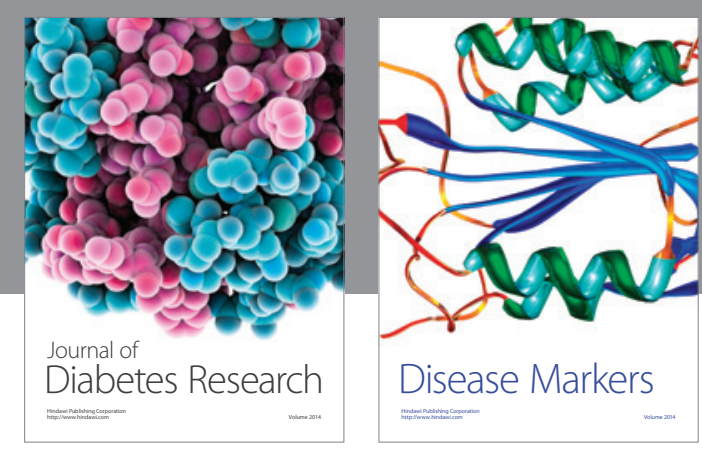

Disease Markers
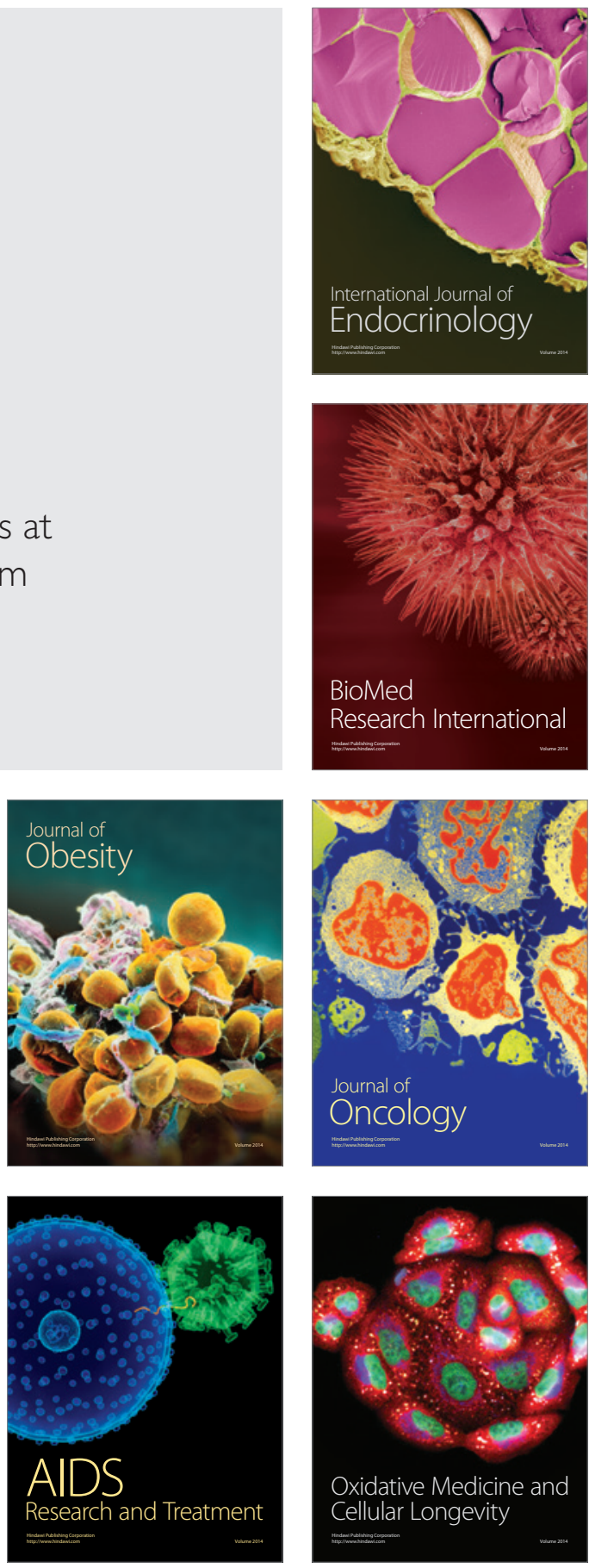